\title{
MALIGNANT HYPERTENSION IN A CHILD DUE TO UNILATERAL KIDNEY DISEASE
}

\author{
BY
}

\author{
C. ISAACSON and S. WAYBURNE
}

From the South African Institute for Medical Research and Baragwanath Hospital, Johannesburg, South Africa

(RECEIVED FOR PUbliCATION AUgUST 27, 1956)

Unilateral malignant nephrosclerosis appears to be a rare condition. In a review of the literature Manners (1954) was only able to find reports of two cases in children and five cases in adults. This author also reported a further case in a child of 3 years, in whom the most significant finding at necropsy was partial obstruction of the left renal artery at its origin due to swelling of the aortic intima. Whereas on microscopy the left kidney appeared completely normal, the right kidney showed severe malignant nephrosclerosis. The pathogenesis of the aortic intimal swelling was not clear, but the possibility that it represented an organized thrombus was considered.

The rarity of the syndrome prompts us to publish a case from our hospital bearing a close resemblance to that of Manners.

\section{Case Report}

T.T., an 8-year-old African girl, was admitted to hospital on July 1, 1955, with a seven months' history of blurred vision and headaches, and a three years' history of attacks of abdominal pain associated with vomiting occurring at one to two monthly intervals. She had suffered from measles, whooping cough, and ascariasis at an early age, but there was no history of sore throat, haematuria, oedema, dyspnoea or weight loss. Her appetite had been poor for some time.

On admission she was dull and lethargic but appeared to be comfortable in the recumbent position. She was apyrexial, her weight was $42 \mathrm{lb}$., and though of slight build, there was no evidence of nutritional, skin or hair changes, and there was no oedema or hepatomegaly.

The heart was enlarged, the apex impulse heaving in character, and a triple rhythm was present. The rate was 100 and the blood pressure $235 / 185 \mathrm{~mm}$. $\mathrm{Hg}$ in the right arm, and in both legs was $260 / 220 \mathrm{~mm}$. Hg. The femoral pulses were easily palpable and there was no evidence of cardiac failure. Electrocardiography confirmed a gross left ventricular hypertrophy.

The fundi showed a severe grade IV retinitis with haemorrhages, typical macular stars and widespread macular oedema. A catheter specimen of urine contained a heavy deposit of protein, the specific gravity was
1022 and microscopic examination revealed hyaline casts, epithelial cells, occasional red cells and 2 to 3 polymorphonuclears per high-power field. The blood urea was $43 \mathrm{mg} . / 100 \mathrm{ml}$., the haemoglobin $14.7 \mathrm{~g} . \%$ with a normal leucocyte count. The serum sodium was 118 $\mathrm{mEq}$./litre, the serum potassium $4.1 \mathrm{mEq}$./litre and the plasma chlorides $102 \mathrm{mEq}$./litre.

Intravenous pyelography showed a large but apparently normal right kidney and pelvis, and a poorly functioning left kidney which showed up faintly 60 minutes after injection of the dye (Fig. 1). A retrograde pyelogram was attempted but catheterization of the left ureter was unsuccessful. The bladder was normal. Tests for

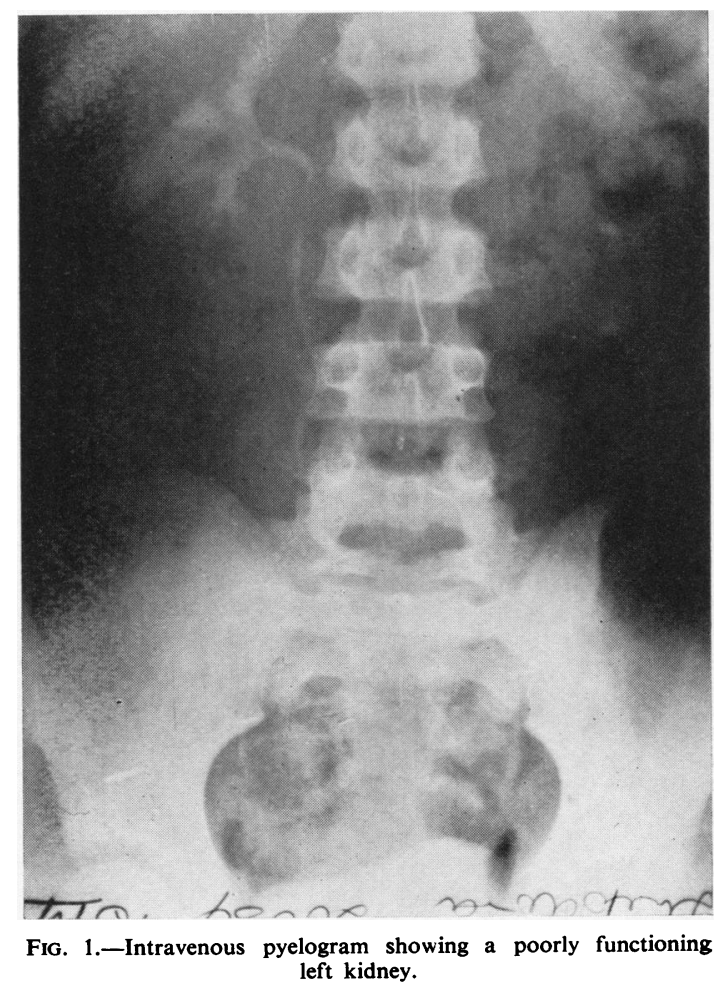


phaeochromocytoma were negative and in view of persistent severe hypertension and apparent deficient left kidney function it was considered advisable to remove the left kidney.

The child was given a slow intravenous infusion of $5 \%$ dextrose before operation to facilitate control and the administration of medicaments during anaesthesia.

At operation, eight days after admission, the left kidney was found to be small, hard, compressed against the vertebral column and lying almost transversely. No aberrant renal vessel or ureteric anomaly was present, and there was no evidence of any inflammatory process. The suprarenal gland was normal. A left nephrectomy was performed. The pathological report on the removed kidney was as follows:

The kidney $(30$ g.) was smaller than normal. The capsule stripped with slight difficulty leaving a finely granular surface. In addition there were a few deeper cortical scars. On section there was no alteration in the cortico-medullary ratio, but there was slight congestion of the cortex and medulla. Microscopically, an occasional glomerulus showed complete hyalinization while others showed partial fibrosis with intracapsular adhesions. These changes were focal. The vessels and tubules appeared normal. There were foci of inter- stitial lymphocytic and histiocytic infiltration, especially around the glomeruli and small vessels in the subcapsular region. No abnormality was observed in the pelvis (Figs. 2 and 3 ).

Immediately after nephrectomy the blood pressure dropped to $140 / 120 \mathrm{~mm}$. Hg. Post-operatively the child was given $500 \mathrm{ml} .0 .9 \%$ sodium chloride in $5 \%$ dextrose followed by $500 \mathrm{ml} .5 \%$ dextrose. The day after operation the serum sodium level was $128 \mathrm{mEq}$./litre, the serum potassium level $5.0 \mathrm{mEq}$. and the blood urea level had risen to $121 \mathrm{mg} . / 100 \mathrm{ml}$. She had passed no urine up till 24 hours after operation and catheterization produced $3 \frac{1}{2}$ oz. of dark bloody fluid. No bowel movement had taken place, but there was no vomiting or distension. The blood pressure at this time was $150 / 110 \mathrm{~mm}$. $\mathrm{Hg}$.

Forty-eight hours after operation she vomited, and in the course of the next two days the blood urea level rose to $190 \mathrm{mg} . / 100 \mathrm{ml}$., the serum potassium to $5.9 \mathrm{mEq}$. and the serum sodium dropped to $109 \mathrm{mEq}$./litre. A few watery stools were passed. She was given a further intravenous infusion of $0.45 \%$ sodium chloride in $5 \%$ dextrose. The blood pressure rose to $180 / 120 \mathrm{~mm}$. $\mathrm{Hg}$ and she continued to pass watery stools and a very small quantity of urine each day.

On the ninth post-operative day the condition wor-

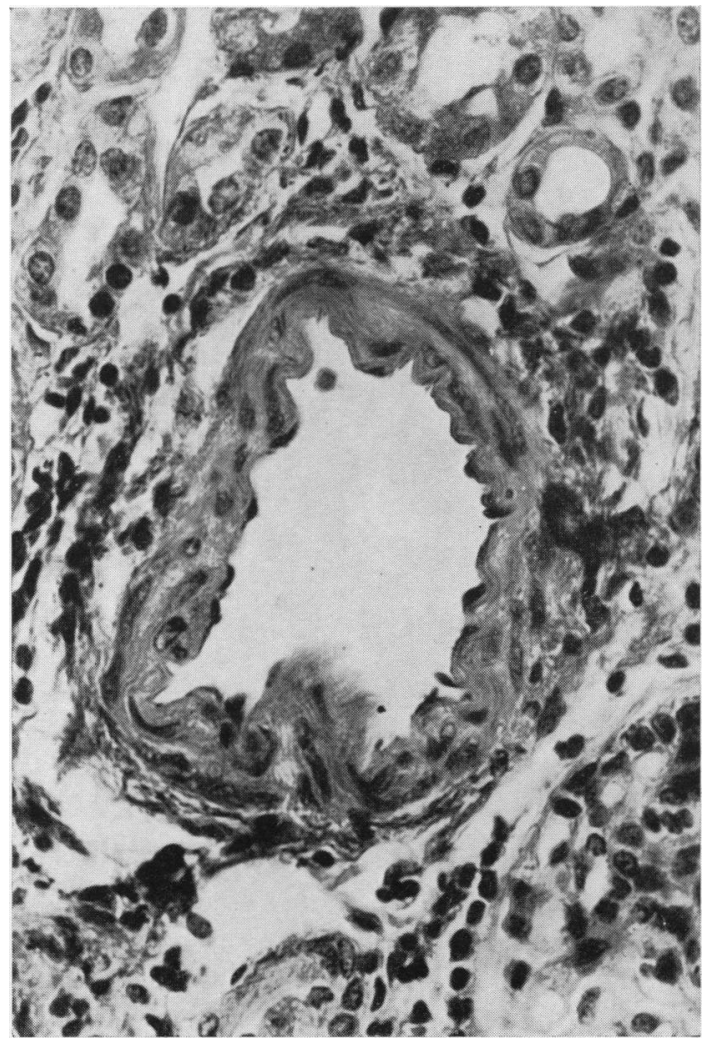

Fig. 3.-High-power view of one of the smaller arteries seen in Fig. 2. Haematoxylin and eosin $\times 400$. 


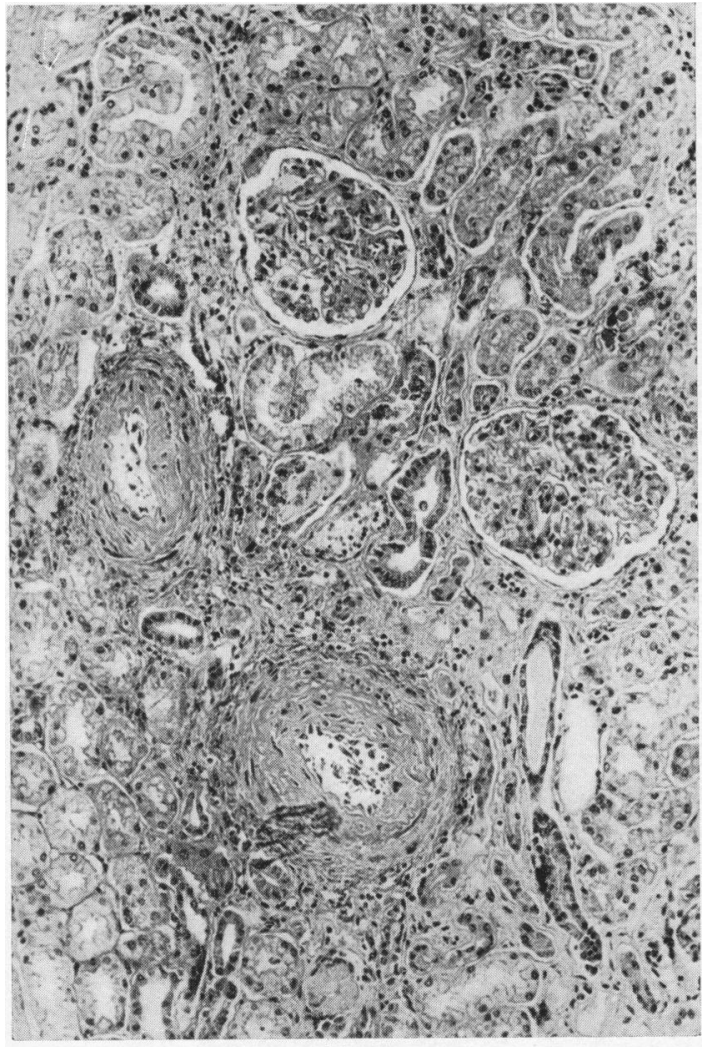

FIG. 4.

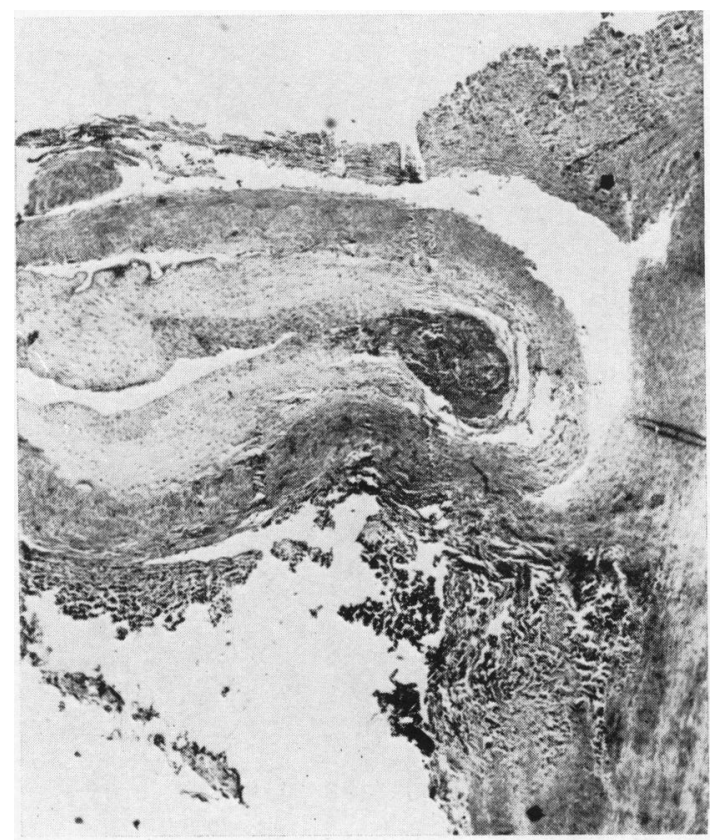

FIG. 6.

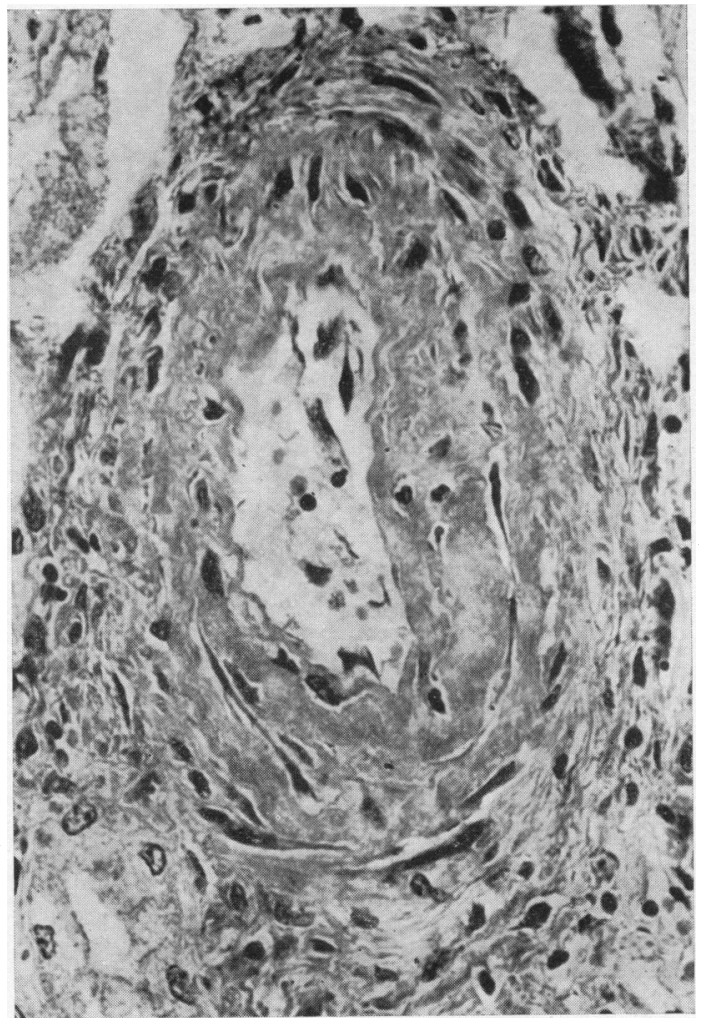

FIG. 5.

FIG. 4.-Section of the right kidney showing well-marked fibrohyaline thickening of the walls of the smaller arteries. Haematoxylin and eosin $\times 100$.

FIG. 5.-High-power view of one of the smaller arteries seen in Fig. 1. Haematoxylin and eosin $\times \mathbf{4 0 0}$.

Fig. 6.-Section of the left renal artery at its origin showing the marked fibrous intimal hyperplasia with considerable narrowing of the lumen. In addition a recent ante-mortem thrombus is present on the right of the photograph. Haematoxylin and eosin $\times 25$. 
sened, the blood urea level was $295 \mathrm{mg} . / 100 \mathrm{ml}$., the total daily output of urine $180 \mathrm{ml}$. (protein present, and specific gravity 1006). The patient was put on to Bull, Joekes and Lowe's (1949) diet, but she deteriorated further, becoming incontinent of urine on the eleventh post-operative day, passed loose melaena stools, and became comatose, the blood urea having risen to 315 $\mathrm{mg} . / 100 \mathrm{ml}$. The serum sodium level remained low (118 mEq.), the potassium level was $4.0 \mathrm{mEq}$./litre and the $\mathrm{CO}_{2}$-combining power $14 \mathrm{mEq}$./litre. Further administration of intra-gastric drip feeds was prevented by persistent vomiting, and no improvement resulted from intravenous administration of sodium chloride solution and blood transfusion. She died on the seventeenth day after operation with signs of uraemia and left lower lobe pneumonia.

\section{Post-mortem Findings}

External Examination. The body was that of a thin, female African child, with a recent left paramedian supra-umbilical surgical incision $4 \frac{1}{2}$ in. long.

The Left Kidney. The left kidney had been surgically removed before death as is described above. The left renal artery had been surgically ligated with catgut $2 \mathrm{~cm}$. from its origin. At its origin from the aorta and for a distance of about $5 \mathrm{~mm}$. the vessel was markedly narrow, being about $1 \mathrm{~mm}$. in diameter. Distal to this narrowing the vessel was of normal calibre and contained a recent ante-mortem red thrombus. The aorta in the region of the origin of the left renal artery showed mild fatty streaking, the streaks being distal to the ostium.

The Right Kidney. The right kidney, 70 g., showed marked pallor of both cortex and medulla but no other significant lesion. The right renal artery contained a recent ante-mortem red thrombus about $\frac{1}{4}$ in. long.

The Bladder. The bladder showed an acute cystitis.

The Heart. The heart, 150 g., was markedly enlarged due to concentric hypertrophy of the left ventricle. On section the myocardium appeared healthy (left ventricle $11 \mathrm{~mm}$., right ventricle $1 \mathrm{~mm}$.). There was no obvious lesion in the valves and endocardium. The coronary arteries were healthy. The ductus arteriosus and foramen ovale were both closed. The pericardial sac was normal. The pleural cavities contained a slight excess of straw-coloured fluid and the lungs (R. $160 \mathrm{~g}$., L. $110 \mathrm{~g}$.) showed marked congestion.

The Peritoneal Cavity. This showed an acute generalized peritonitis.

The Liver. The liver, 800 g., presented a yellowishbrown appearance suggestive of diffuse fatty change.

\section{Microscopic Examination}

The Right Kidney. The right kidney showed marked fibrohyaline thickening of the walls of the smaller arteries. The afferent arterioles appeared normal. In addition an occasional glomerulus was hyalinized and many of the

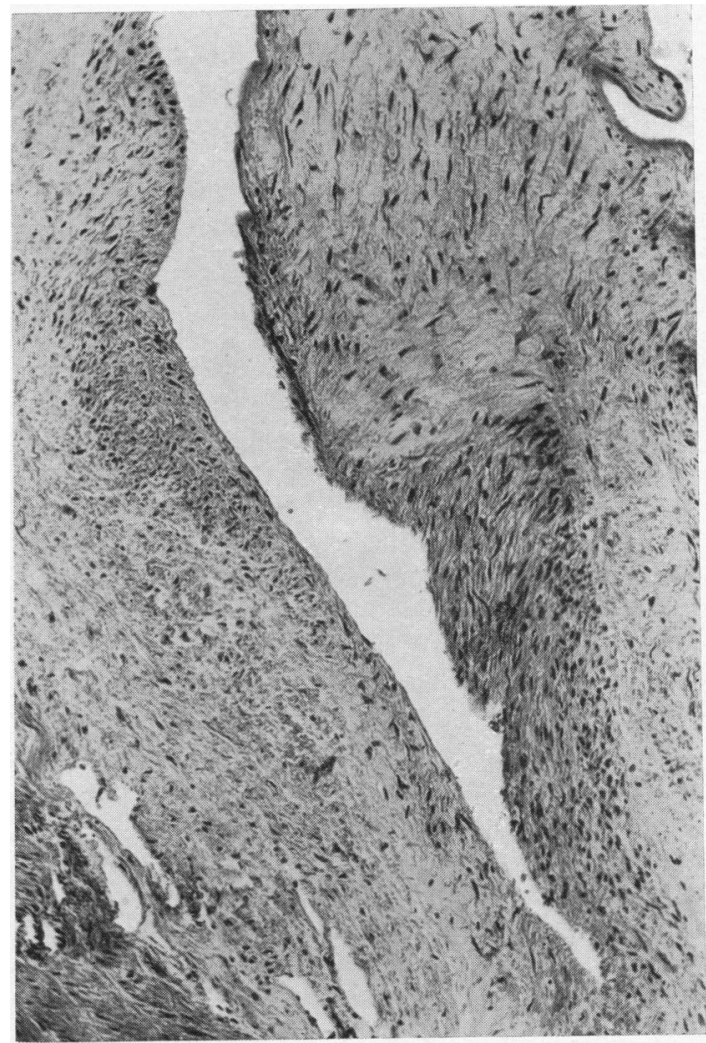

FIG. 7 - High-power view of the left renal artery showing the marked fibrous thickening of the intima. Haematoxylin and eosin $\times 100$.

tubules were dilated and contained hyaline casts. The features were those of a severe nephrosclerosis (Figs. 4 and 5).

Right Renal Artery. The right renal artery showed considerable fibrous intimal hyperplasia and contained a large recent ante-mortem thrombus.

Left Renal Artery. Serial sections of the left renal artery showed marked thickening of the wall at its origin with considerable diminution in the size of the lumen due to old fibrous intimal hyperplasia. In addition, a recent ante-mortem thrombus was also observed. Beyond this area the lumen was of normal diameter (Figs. 6 and 7).

The Heart. The heart on section showed marked hypertrophy of the muscle fibres of the left ventricle.

The Liver. The liver showed diffuse fatty change, and section of the peritoneum showed the histological features of an acute peritonitis.

\section{Discussion}

Although no foci of fibrinoid necrosis were observed in the arterioles or glomeruli of the right 
kidney, we feel that the presence of papilloedema and exudates with failing vision, and the severity of the hypertension justify, on clinical grounds, the diagnosis of malignant as opposed to benign hypertension.

The pathogenesis was almost certainly that of a partial obstruction to the left renal artery producing ischaemia of the left kidney with release of pressor substance and resulting hypertension. The marked nephrosclerotic changes produced in the right kidney were not present in the left kidney, as the latter was protected from the effects of the hypertension by the narrowed left renal artery. In effect this case was the human counterpart of the animal experiments of Goldblatt (1948) and Wilson and Byrom (1939). The aetiology of the fibrous intimal thickening of the left renal artery was not clear but may have been due to organization of an old thrombus or a reaction to anoxia.

According to Braasch (1942) less than $1 \%$ of patients with hypertension are amenable to therapy for hypertension by nephrectomy, and of 198 patients with hypertension due to unilateral kidney disease who underwent nephrectomy, 65 showed normal blood pressures post-operatively for one year or more. Allen (1952) states that the frequent failure to relieve hypertension by surgical removal of an abnormal kidney is probably due to the development of arteriosclerotic lesions in the opposite normal kidney as a result of the hypertensive state. It is theoretically possible that in such instances an earlier nephrectomy might prevent the development of contralateral renal arteriosclerosis with the resultant vicious circle of hypertension, renal ischaemia and more hypertension. It is clear then that nephrectomy in uni- lateral kidney disease can only bring relief of hypertension if the condition is discovered early. Depending, moreover, on the state of the retained kidney, hypertension may occasionally be made worse by nephrectomy. It is in such cases that renal biopsy may be of great value, and would in our case, for example, have clearly demonstrated the severity of the arterial lesions in the right kidney and the futility of left nephrectomy. Taken in conjunction with the intravenous pyelogram such a biopsy finding would have suggested, instead, an exploratory laparotomy to assess the state of the left kidney and renal artery.

\section{Summary}

A case of malignant nephrosclerosis in a child due to partial occlusion of the left renal artery is described. Whereas the right kidney showed severe nephrosclerosis, the left kidney presented minimal histological changes. In addition there was generalized arteriosclerosis with left ventricular hypertrophy. The patient died from acute peritonitis following removal of the left kidney. It is suggested that renal biopsy may be of value in such cases.

We wish to thank Dr. J. Benatar, Senior House Physician, for considerable personal endeavour, and the photographic department of the South African Institute for Medical Research for the photomicrographs. Mr. C. D. Kisner operated and Dr. H. Clain made the radiological examinations.

\section{REFERENCES}

Allen, A. C. (1951). The Kidney. New York.

Braasch, W. F. (1942). Canad. med. Ass. J., 46, 9.

Bull, G. M., Joekes, A. M. and Lowe, K. G. (1949). Lancet, 2, 229.

Goldblatt, 'H. (1948). The Renal Origin of Hypertension, pp. 18 and 33. Publ. No. 14, American Lecture Series. Springfield, Illinois.

Manners, T. (1954). J. Path. Bact., 68, 63.

Wilson, C. and Byrom, F. B. (1939). Lancet, 1, 136. 